American Journal of Pharmaceutical Education 2019; 83 (8) Article 6866.

\title{
RESEARCH
}

\section{Study Abroad Course for Pre-pharmacy and Pharmacy Students to Learn About Global Health}

\author{
David M. Scott, PhD, Cynthia Naughton, PharmD, Kelly Haugen, MS, Daniel L. Friesner, PhD \\ School of Pharmacy, College of Health Professions, North Dakota State University, Fargo, North Dakota \\ Submitted November 1, 2017; accepted July 19, 2018; published October 2019.
}

Objective. To design, implement, and assess a study abroad course in Ireland for pre-professional and Doctor of Pharmacy (PharmD) students.

Methods. An elective study abroad course was created for pre-professional and PharmD students at North Dakota State University. The course included comparison of the US and Ireland's health care delivery systems and participation in history and cultural experiences in Ireland. Prior to the trip, students and preceptors attended seminars related to the culture of Ireland. The three-week trip to Ireland took place between the spring and summer semesters in 2016. Student assignments while abroad included completion of a self-reflection journal with daily entries describing what the student learned and how the experience impacted them, and completion and presentation of a term paper comparing Ireland's pharmacy system with that in the United States. Pre- and post-travel surveys were conducted to assess students' perceptions of and learning from the experience, and to identify areas for course improvement.

Results. Students' evaluations of the course and travel experiences were positive. However, students' perceptions of their cultural awareness were largely unchanged.

Conclusion. The course was well received by students. Other PharmD programs may benefit from implementing similar study abroad experiences.

Keywords: educational assessment, comparative health delivery systems, global education, global health, pharmacy education

\section{INTRODUCTION}

Global health refers to "the area of study, research and practice that places a priority on improving health and achieving equity inhealth for all people worldwide." ${ }^{1-5}$ Priority global health areas for the World Health Organization (WHO) include prevention and treatment of both communicable diseases (eg, HIV, tuberculosis, malaria) and chronic diseases (eg, heart disease, diabetes, mental health conditions). ${ }^{6}$ Since health systems around the world differ, it is beneficial for pharmacists to learn how their colleagues in other countries who have different levels of education, different scopes of practice, and face different payment systems, provide pharmacy services and manage chronic conditions. To address this issue, the International Pharmaceutical Federation (FIP) is collaborating with the World Health Organization and the United Nations Educational, Scientific, and Cultural Organi-

Corresponding Author: David Scott, Departments of Pharmacy Practice and Public Health, School of Pharmacy, College of Health Professions, North Dakota State University, Fargo, ND. Tel: 701-231-5867. E-mail: david.scott@ndsu.edu zation (UNESCO) on a Global Pharmacy Action Plan to "expand the role of pharmacists in public health; allow for a global exchange and analysis of experiences; and, appropriately train pharmacists to assist with globalization of the profession." 8,9

In 2009, the American Association of Colleges of Pharmacy (AACP) called for an expansion of studentpharmacist involvement in global health ${ }^{10}$ and developed a strategic plan for and special interest group on global health. ${ }^{11-13}$ The AACP, in partnership with the Accreditation Council for Pharmacy Education (ACPE), established a goal to advance the quality of pharmacy practice and pharmaceutical education worldwide. ${ }^{11}$ Doctor of Pharmacy (PharmD) programs are now tasked with integrating global health into their curricula and, if possible, providing opportunities for faculty members and students to engage in global experiences. For programs unable to integrate global health into their required curriculum, elective courses provide a viable alternative. Such coursework must be consistent with ACPE accreditation guidelines, which emphasize an outcomes-based approach to ensure optimal student learning. ${ }^{14}$ 


\section{American Journal of Pharmaceutical Education 2019; 83 (8) Article 6866.}

The literature regarding the implementation and assessment of global health content in US PharmD programs is relatively sparse. In 2016, Bailey and DiPietro completed a systematic website search of global health content in the didactic and experiential curricula of 133 US PharmD programs. ${ }^{15}$ Inclusion of global health topics in PharmD programs varied widely. More than 50 programs offered an elective course related to global health; eight offered a required course; eight offered a minor or certification in global health; and three offered dual degrees in pharmacy and global health. The most formalized global health opportunities were integrated with didactic course work, such as having students initially participate in lectures related to their planned experience, and culminating in application of studied topics within an international experience. More than 50 programs offered experiential education opportunities in global health, including international advanced pharmacy practice experiences (APPE) or medical mission trips. One of the primary recommendations made by AACP and ACPE is to establish a standardized curricular framework to facilitate pharmacists' competently assuming greater responsibilities in the global health arena. Second, the authors recommended that greater emphasis on global health education research within PharmD curricula is needed. ${ }^{15}$

In 2016, Steeb and colleagues described experiential and didactic educational opportunities in schools and colleges of pharmacy in the United States. ${ }^{16}$ They conducted a two-stage, web-based review and then contacted the identified schools to confirm their offerings. Of the responding schools, $64 \%$ reported having an advanced pharmacy practice experience (APPE) in a foreign country (one of 67 different countries covered) and 47\% confirmed having a globally focused course offering. The majority of these courses were interprofessional. ${ }^{16}$

In 2017, Prescott and colleagues reported on a survey of global health activities in 127 PharmD programs in the US. ${ }^{17}$ Twenty-eight public institutions and 27 private institutions responded to the survey (43.3\%). Twenty-five $(45.5 \%)$ programs had integrated global health topics into their required didactic curriculum, and 30 of 52 programs $(57.7 \%)$ offered at least one standalone global health elective course. Of the 52 programs that provided details regarding experiential education, $41(78.8 \%)$ offered introductory and/or advanced pharmacy practice experiences (IPPEs and/or APPEs) in global health, and 34 (65.4\%) programs offered medical mission trips. ${ }^{18}$ None of these programs offered coursework that combined didactic and experiential education; a crucial missing link in the educational process. The authors recommended that, to effectively prepare students for an increasingly global society, PharmD programs should continue to expand global health education, including greater integration of classroom and experiential learning opportunities. ${ }^{17}$

A critical learning outcome for pharmacy students is to develop an understanding and appreciation for other cultures, as all clinicians in the US serve increasingly diverse patient populations. Becoming aware of how the history, cultures, and perspectives of their patients' frame health care decisions, especially as they relate to the utilization of health services and compliance with provider recommendations, allows clinicians to frame patient interventions in a manner that increases their effectiveness. Providing global health learning opportunities will enhance students' cultural sensitivity and help them toward ultimately achieving cultural competency.

In many academic disciplines, cultural immersion is often developed through study abroad experiences. Generally, study abroad experiences differ from those discussed previously (APPEs, medical mission trips) in that they focus on a traditional, discipline-specific area of study, and combine both didactic and experiential learning (for an example, see https://www.iesabroad.org/ study-abroad). Professional pharmacy programs often find it difficult to implement study abroad experiences because of the length, structure, and lack of flexibility in their academic programs. Cultural immersion experiences that do exist often occur through medical mission work ${ }^{16-18}$ and require students to have completed the majority of their programs of study to be able to contribute meaningfully to the mission. This is also insufficient, as students become more culturally competent when they have repeated opportunities to study abroad throughout their curriculum.

Despite several reports on the need for more global education, particularly study abroad experiences, the pharmacy education literature is rather devoid of evidence-based reports describing how existing programs are delivered and the impact of these experiences on students. This represents an important gap in the literature. While study abroad programs are not the only means to address this gap, they are a very flexible way to provide global education and cultural immersion opportunities. Study abroad programs may also incorporate didactic and/or experiential learning, and thus complement other educational opportunities offered in the student's home country.

This paper describes the experiences of the North Dakota State University (NDSU) School of Pharmacy in developing, implementing, and assessing a global health course for pharmacy students intended to help them develop an appreciation of global cultures and compare the health care delivery system and pharmacy practice in Ireland with that in the US. Comparisons of 


\section{American Journal of Pharmaceutical Education 2019; 83 (8) Article 6866.}

the health care delivery systems of two countries presents major challenges, such as comparing the outcomes of the two health systems when a paucity of data exist to characterize outcomes, and accounting for different values in the countries studied. ${ }^{19}$ Our primary objective was that by completing the course, students would develop an appreciation of these challenges and, in doing so, better understand and appreciate the US health system.

\section{METHODS}

The NDSU PharmD program developed a study abroad program specifically for pharmacy students. Students at all levels were eligible to participate. The program focused on study abroad experiences that emphasized the practice of pharmacy internationally, especially in countries where pharmacy graduates (including those at the master's degree level) were eligible to sit for the foreign equivalency examination and practice in the US. The experience was scheduled for three weeks in May, between the end of spring semester and start of summer sessions. The program was offered for the first time in 2016 by two faculty members and one staff member who took a group of 13 students to Ireland.

Faculty members designed and implemented a 3credit study abroad course sequence taught during the 2016 spring semester entitled, Introduction to Pharmacy Practice: An International Perspective. A decision was made to link the content of the study abroad course to a foundational first-year professional course, Introduction to U.S. Health Care Systems, as we believed that students who completed that course would have a foundation upon which to compare and contrast the practice of pharmacy in other countries. Thus, the health systems course was designated as a prerequisite for the study abroad course. Because prepharmacy students were ineligible to take the prerequisite course, an alternate series of seminars (eg, history of Ireland, overview of the US health care delivery system, health insurance, and interprofessional care) was held for prepharmacy students to complete to ensure that they acquired the requisite knowledge prior to the immersive experience.

The NDSU Doctor of Pharmacy program is an entry level program, consisting of approximately 76-77 credits of pre-professional coursework and four years of study in the professional program. The spring semester concludes in mid-May of each year and is followed by introductory pharmacy practice experiences (IPPEs) or advanced pharmacy practice experiences (APPEs), which typically start in June. Thus, a three-week window existed in which to offer the study abroad course at a time when both preprofessional and professional pharmacy students could participate.
Another critical decision the course faculty members faced was the location for the international experience. A primary consideration was cost. While study abroad experiences are inherently more expensive than traditional education, faculty members wanted to ensure that all study abroad activities provided substantial value for the cost. Also, for the first offering of the course, we wanted to choose a location where it would be easier to organize and implement the logistics of the experience. Finally, many of the students in the NDSU School of Pharmacy had never travelled internationally, and may have found the prospect of travelling to a country that was substantially (both geographically and culturally) different from the US be a daunting experience. Based on these considerations, faculty members and administrators determined that traveling to locations in Europe would be best for the first few study abroad experiences offered. European locations meant lower travel expenses (relative to Asia or Australia, for example), reduced travel times, and easier coordination of logistics. Finally, students were sufficiently familiar with European culture to enable them to more easily compare and contrast the host country's health system to that of the US.

Each study abroad program presents a unique set of logistical challenges. The faculty members designing this study abroad program did not have the technical acumen to manage this process on our own. Therefore, we made a decision to partner with the Institute for International Education of Students (IES Abroad, https://www.iesabroad.org/) to help with implementing the program as other academic programs at NDSU had done in the past. The role of IES Abroad was to identify partner institutions, provide living accommodations, and work with faculty members to offer appropriate cultural immersion experiences to students. The IES also worked closely with both faculty members and the NDSU Office of International and Study Abroad Services to manage program costs. More specifically, we provided a "wish list" of experiential learning activities, and staff at IES not only provided multiple options (including travel, tours, and guest speakers), but also provided detailed cost estimates for each option so that faculty members could appropriately judge the value of each opportunity. Another reason for the faculty members' decision to work with IES Abroad was our intent to offer the study abroad course in different countries in the future. This would allow students to repeat the course, yet amass different pharmacy and cultural experiences each time.

Based on consultations with IES Abroad, Dublin, Ireland, was chosen as the site to offer the course for the first time in 2016. Locations chosen for future study abroad experiences were London, United Kingdom (in 


\section{American Journal of Pharmaceutical Education 2019; 83 (8) Article 6866.}

2017) and Vienna, Austria (in 2018). Costs for the 2016 Ireland study abroad experience, not including airfare and payments for academic credit at NDSU, were approximately $\$ 2,800$ per student. Costs for airfare varied based on student departure and arrival dates/times, but were generally around $\$ 1,000$ per person. Payments for academic credit also varied based on professional/pre-professional status, but also were approximately $\$ 1,000$. In terms of value, the NDSU Office of International and Study Abroad Services requires that study abroad courses include a minimum amount of didactic and/or experiential education per credit hour earned. Working with IES allowed us to exceed these thresholds by approximately $25 \%$ to $30 \%$ without noticeably increasing student costs.

The course's eight objectives were mapped to course content delivered in the prerequisite course, PHRM 352, but emphasized comparing and contrasting health systems in the US and Ireland as follows: compare health care delivery and medication use in Ireland with the US system; describe an overview of the United States' and Ireland's health care industry (eg, hospitals, ambulatory care, long-term care, mental health care, public health system) and their various responses to health care diseases and problems; explain the history, functions and impact of major components of health care financing (eg, insurance, Medicare, Medicaid programs) in the US and compare them with those in Ireland; describe the history of governmental efforts to prevent and control the problems of health and disease, as well as the professional's role in public health; compare the roles of the Food and Drug Administration (FDA) and other agencies in global health; describe the potential impact of cultural values, beliefs, and practices on healthcare delivery and health outcomes; evaluate one's personal and professional values and career plans within the global context; and demonstrate written and verbal communication skills regarding issues related to health and drug policy. Table 4 contains a summary of these objectives.

The seminar series held in Ireland covered the Ireland health care system including the public sector that is available for all Irish citizens (hospital care and primary care physician services). Ireland also has a private sector health care system through which wealthier citizens may purchase a private insurance plan to avoid longer wait times for certain specialist appointments and surgeries. Other seminar topics included the changing US health care system, global health and disease, and comparative health in Canada and the United Kingdom. Comparative pharmacy education was presented by our faculty members and a guest speaker (pharmacy educator) from the Trinity College of Dublin. Pharmacy practice seminars were given by a guest speaker from the Irish Pharmacy
Union (a professional organization), and another by the Pharmacy Regulator of the Pharmacy Society of Ireland (PSI). The first observation was that Ireland had moved towards a 5-year master's degree program in pharmacy $(4+1$ structure). The additional year would be spent completing the National Pharmacy Internship Program, which includes experiential learning in community, hospital, and/or pharmaceutical industry settings. A second observation was that the pharmacy regulator (who reports to the Minister of Health) was very influential in both pharmacy education and practice in Ireland. The Pharmacy Society of Ireland is responsible for licensing pharmacists, setting standards of practice, and accreditation of education institutions. The Ireland national health system typically encourages patient care by the community pharmacist. Given the need to reduce pressures (waiting times) on primary care providers, there is greater reliance on other health professionals (eg, pharmacists) to improve access to care. Accordingly, Irish regulators typically push for higher pharmacy practice standards in some patient care and public health areas. For example, in the three community pharmacies we toured, community pharmacists can diagnose streptococcal pharyngitis, run methadone clinics, administer immunizations (influenza, pneumococcal), and administer emergency medications (eg, hormonal contraception, epinephrine, and naloxone). The community pharmacies in Ireland are typically smaller than those in the US and tend to be independently owned.

Student learning during the study abroad experience was assessed in both the cognitive and affective domains. Each student identified a topic of interest (eg, health system structure, policy, or public health issue) that was relevant to pharmacists practicing in both Ireland and the US. Students had to independently write a term paper (literature review using peer-reviewed academic sources) that characterized and critically analyzed the topic area. The paper topic had to be preapproved by the course instructor. Students then presented their literature review paper to the rest of the class during the final week of the study abroad experience. The written literature review and class presentation was graded using a rubric. The rubric items assessed the student's ability to research and synthesize the topic, and addressed the strengths and weaknesses of the references, the clarity and consistency of the writing, and the student's research, insight, and presentation skills. Poor grammar, spelling mistakes, inconsistency, and/or poor logic reduced the score.

In addition to the paper, students were required to maintain a daily journal in which they record activities and cultural experiences encountered during their 21 days in Ireland. This included didactic lectures, pharmacy visits, cultural events, field trips throughout Ireland, and 


\section{American Journal of Pharmaceutical Education 2019; 83 (8) Article 6866.}

weekend visits. Because the goal of these activities was to provide students with an opportunity to reflect upon and synthesize how sociocultural and political differences between the US and Ireland impacted the provision of pharmacy services within these two countries, students were given latitude in how they recorded these events. Some students included both text and pictures, while others just included text.

Given the nature of the course and the small expected enrollment (less than 20 students typically enroll in a study abroad course), learning outcomes were assessed descriptively. The survey instrument was designed primarily by the first author, and versions were reviewed by each author to include perceptions of global travel and cultural competence using validated scales. ${ }^{20-22}$ Students were surveyed before and after the study abroad experience. The pretravel survey was designed by the course faculty members and solicited students' perceptions regarding global studies, course design, elements of instruction, and development of the study abroad experience. Students were asked to rate their level of interest based on a 5-point Likert scale on which $1=$ not at all interested and $5=$ very interested. Demographic information was also collected using items adapted from published studies. ${ }^{22}$ The pre-travel survey was sent out in early May, just prior to the trip. Reminders were sent three times over a 10-day period to ensure an adequate response rate. ${ }^{22-24}$

Students completed the surveys electronically through the Qualtrics (Provo, UT) online survey administration platform. Clicking on the link to the survey and completing the survey was considered consent to participate in the study. A similar post-travel survey was designed by faculty members and administered at the completion of the course in early June, after students had returned from the trip. In the section describing course format, students were asked to rate each item using a fivepoint Likert scale on which $1=$ very weak to $5=$ very strong. Students were also asked to rate their level of agreement with a series of global interest areas $(1=$ strongly disagree to $5=$ strongly agree). For each course topic, each student was asked to indicate how useful each topic (experience) would be to their pharmacy career $(1=$ not at all useful to $5=$ very useful). The post-survey included items about the Ireland experience, including onsite didactic learning, field experiences that included pharmacy visits, pharmacy education, and the pharmacy regulatory agency in Ireland.

In the post-test survey, for the scale of items measuring cultural competence, the students were asked to rate each item that best represented their thoughts $(1=$ strongly agree to $5=$ strongly disagree or not applicable). This scale from the Health Professionals scale was adapted from Rose. ${ }^{20}$ Students were also asked to rate each of the six dimensions of cultural competence using the Global Learning Value Dimension on a scale where $1=$ lack awareness to $5=$ full awareness and knowledgeable. ${ }^{21}$ Lastly, students were asked to rate various aspects of their study abroad experiences using discrete response and open-ended survey items.

Descriptive statistics were used for survey responses and pre-post changes in specific survey responses related to growth of global and cultural awareness. Because of the small sample size $(\mathrm{N}=13)$, all students' survey responses were included in the analysis whether or not a student completed both the pre- and post-travel surveys. Thus, the sample was unmatched. Analysis of variance (both parametric and nonparametric) was used to assess changes in global or cultural awareness in a non-matched format. In all cases, a null hypothesis of no pre-post changes in mean global/cultural awareness occurred. ${ }^{25}$ All hypothesis tests used a five percent significance level and were conducted using IBM SPSS Statistics, version 24 (IBM Corporation, Armonk, NY).

An informal analysis of the qualitative comments and overall student ratings of the study abroad experience was included. Faculty and staff read each student journal and paper, and only those themes that all faculty and staff members identified were included here. The study procedures were reviewed and approved as exempt by the NDSU Institutional Review Board.

\section{RESULTS}

Thirteen students, two faculty members, and one advisor participated in study abroad course during the spring 2016 semester. All 13 students completed the literature review, the journaling, and the reflection paper. Of these 13 students, one student did not participate in a full set of assessment activities, and another student completed the pre-survey but not the post-survey. Thus, we had a sample size of 12 for the pre-travel survey and 11 for the posttravel survey.

To compare health care systems in Ireland and the US, each student selected one of the following topics and authored a paper and verbal presentation on the topic: health system costs, prescription costs, mental health, long-term care, or pharmaceutical care programs. Presentation of the paper was worth 50 points, and the mean score was $46.0(\mathrm{SD}=1.9)$. The term paper was worth 100 points, and the mean score was $94.2(\mathrm{SD}=2.6)$.

Each student submitted a reflection paper that summarized his or her daily experiences in Ireland. Most students completed the paper using both textual content and photographs. Out of a possible 50 points, students' mean 


\section{American Journal of Pharmaceutical Education 2019; 83 (8) Article 6866.}

score was $49.4(\mathrm{SD}=0.8)$. Several themes were identified by all of the faculty members when examining the journal entries and the paper. Students' reflections focused primarily on the cultural immersion experiences and secondarily on academic learning experiences. One major theme was that the three weeks of immersion in the Irish culture was an overall positive experience. It was evident from the journal entries that students recognized early in the experience that the Irish had a fundamentally different understanding of an appropriate work/life balance than Americans did. In terms of what students liked about Ireland, themes included the generous portions of food served in restaurants at reasonable prices, the scenery as experienced in the tours taken outside of Dublin, the rich history displayed throughout Dublin, and the emphasis on traditional recreational activities, including traditional Gaelic games. The students found the pharmacy speakers and business tours to be informational and felt they provided an accurate and comprehensive characterization of health care and pharmacy education in Ireland. Most of the students were surprised that walking is the most common mode of transportation in Dublin. The majority of students noted in their reflections that functional, comfortable shoes, quality blister prevention, and first aid were essential while visiting Ireland. The students looked forward to returning to Ireland in the future with family and/or friends. By day 18, many of these same students also noted that they were looking forward to returning home.

Descriptive statistics for items included in the pretravel survey are presented in Table 1. Twelve of the 13 students completed the pre-travel survey. Most of the respondents responded "very high" to the item asking them to rate their desire to travel (mean $=4.9, \mathrm{SD}=0.3$ ). Students also reported a "positive travel experience in the United States" (mean $=4.7, \mathrm{SD}=0.5)$ and "if they traveled outside the United States this was a positive experience" (mean $=4.0, \mathrm{SD}=1.5$ ). Learning about another culture, availability of the Internet to "stay in contact with home," and "learning more about myself" were commonly rated high (mean over 4.0). Most of the students were female (11 of 13). Three were pre-professional students, one was a first-year student, six were second-year students, and three were third-year students in the program. Some of the students were from urban settings and others were from rural settings. Most students reported an interest in practicing in a hospital pharmacy when they graduated, while the remainder planned to practice in an independent or chain community pharmacy. In terms of their desired role in pharmacy, most students aspired to work as a clinical pharmacist, followed by a pharmacy staff member or pharmacy manager.
Items from the post-travel survey are presented in Table 2. The majority of respondents strongly agreed that "The study abroad was a completely new topic to me" (mean $=4.5, \mathrm{SD}=0.7)$, and that "pharmacists need to know how to evaluate and interpret comparative health systems" (mean $=4.0, \mathrm{SD}=0.6)$. Reported satisfaction levels with study abroad activities were highest for community pharmacy visits, followed by the pharmacy research center and guest speakers, pharmacy education, term paper presentations, and comparative pharmacy education (US vs Ireland). The overall quality of the course (mean $=4.6, \mathrm{SD}=0.5)$ and overall quality of the instructors (mean $=4.5, \mathrm{SD}=0.8$ ) were rated very good by most students. Both course faculty members received very high positive satisfaction ratings, as did the staff member.

Table 3 presents an analysis of the pre-travel and post-travel cultural awareness and global awareness survey items. For each cultural awareness item, students were asked to indicate the statement that best represented their thoughts $(1=$ strongly agree to $5=$ strongly disagree, or not applicable) and the same scale was used in both the pre- and post-travel scale. Thus, lower mean values indicate more affirmative responses, and reductions in mean values in post-travel survey responses relative to pre-travel survey responses indicate gains in perceived cultural awareness. For each global awareness item, students were asked to indicate the statement that best represented their thoughts $(1=$ lacks awareness to $5=$ full awareness or knowledgeable, or not applicable). Thus, higher mean values indicated more affirmative/aware responses. Also, gains in mean values in post-travel survey responses relative to pre-travel survey responses indicated gains in perceived global awareness. As with the cultural awareness items, the same scale was used in both the pre- and post-travel surveys.

For the pre-travel survey, the cultural awareness items with which students agreed most strongly were, "I am interested in attending cultural competency/ proficiency workshop" (mean $=2.5, \mathrm{SD}=1.7)$, followed by, "I accept that religion and other beliefs may influence how families respond..." (mean $=2.6, \mathrm{SD}=1.7$ ), and "I have difficulty communicating with patients that cannot speak English...," Regarding global awareness, the three items students felt the most knowledgeable of were "Perspective taking: The ability to engage and learn from other perspectives..." (mean $=4.3, \mathrm{SD}=0.6)$, "Personal and social responsibility: The ability to recognize one's own..." (mean=4.2, $\mathrm{SD}=0.7)$, and "Cultural diversity: The ability to recognize the influences of one's own culture. .." (mean $=4.0, \mathrm{SD}=0.7)$. 


\section{American Journal of Pharmaceutical Education 2019; 83 (8) Article 6866.}

Table 1. Responses of Pre-professional and PharmD Students to Items on a Pre-Travel Survey Administered as Part of a Study Abroad Course in Ireland $(\mathrm{N}=12)$

\begin{tabular}{|c|c|}
\hline Survey Item & Response \\
\hline \multicolumn{2}{|l|}{ Motivation for Study Abroad, Mean (SD) ${ }^{\mathrm{a}}$} \\
\hline Desire to travel & $4.9(0.3)$ \\
\hline Positive previous travel experience in the US and desire to do more & $4.7(0.5)$ \\
\hline Positive previous travel experience abroad (outside of US) and desire to do more & $4.0(1.5)$ \\
\hline Availability of scholarships for international study & $2.8(1.5)$ \\
\hline Learning about another culture & $4.6(0.5)$ \\
\hline Availability of internet to stay in contact with home & $4.4(0.9)$ \\
\hline Improve $\mathrm{CV} /$ resume & $3.6(1.3)$ \\
\hline Learning more about myself & $4.1(0.8)$ \\
\hline Desire to gain independence & $3.8(1.3)$ \\
\hline Gain self-confidence & $3.8(0.8)$ \\
\hline Become more mature & $3.4(1.2)$ \\
\hline Family/significant other encouragement & $3.9(1.4)$ \\
\hline Faculty/advisor suggestion & $2.7(1.4)$ \\
\hline \multicolumn{2}{|l|}{ Demographics, $\%$} \\
\hline Gender, female & 80 \\
\hline Age, $18-24$ yrs. & 80 \\
\hline \multicolumn{2}{|l|}{ What year in school? } \\
\hline Proportion pre-professional pharmacy students & 10 \\
\hline Proportion first-year PharmD students & 20 \\
\hline Proportion second-year PharmD students & 30 \\
\hline Proportion third-year PharmD students & 30 \\
\hline Proportion fourth-year PharmD students & 10 \\
\hline \multicolumn{2}{|l|}{ When you graduate, what pharmacy area are you most interested in: } \\
\hline Hospital pharmacy & 50 \\
\hline Independent community pharmacy & 30 \\
\hline Chain community pharmacy & 20 \\
\hline Other areas of practice & 10 \\
\hline \multicolumn{2}{|l|}{ What best describes your desired position in this pharmacy setting? } \\
\hline Manager & 30 \\
\hline Staff pharmacist & 30 \\
\hline Clinical pharmacist & 40 \\
\hline \multicolumn{2}{|l|}{ What is the population of the city or town in which your home is located? } \\
\hline 50,000 or More & 30 \\
\hline $25,000-49,999$ & 30 \\
\hline $5,000-24,999$ & 0 \\
\hline $2,000-4,999$ & 0 \\
\hline $1,000-1,999$ & 20 \\
\hline $500-999$ & 0 \\
\hline Less than 500 & 20 \\
\hline
\end{tabular}

${ }^{\text {a }}$ Responses based on a scale of $1=$ not at all interested to $5=$ very interested

Within the post-travel survey, the highest rated cultural awareness responses (mean=2.1) included: "I avoid using language that reinforces negative stereotypes" and "I know the definition of cultural proficiency." Regarding global awareness, the three items students felt the most knowledgeable of were "Cultural diversity: The ability to recognize the influences of one's own culture..." $($ mean $=4.5, \mathrm{SD}=0.7)$, "The ability to engage and learn from other perspectives..." (mean $=4.4, \mathrm{SD}=0.7)$, and
"Personal and social responsibility: The ability to recognize one's own. .." (mean $=4.4, \mathrm{SD}=0.7)$.

As reported in Table 3, only one survey item exhibited a significant pre to post difference in survey ratings. The first survey item in the cultural awareness component of the survey, "I plan to display pictures, posters and other materials that reflect. .." exhibited a much higher level of agreement in the post-travel survey (mean $=2.5, \mathrm{SD}=1.2)$ than in the pre-travel survey (mean $=3.7, \mathrm{SD}=1.5$ ). 


\section{American Journal of Pharmaceutical Education 2019; 83 (8) Article 6866.}

Table 2. Responses of Pre-professional and PharmD Students to Items on a Post-Travel Survey Administered as Part of a Study Abroad Course in Ireland $[\mathrm{n}=11]$

\begin{tabular}{|c|c|}
\hline $\begin{array}{l}\text { Survey Item } \\
\end{array}$ & Response \\
\hline \multicolumn{2}{|l|}{ General Study Abroad Perceptions, Mean (SD) ${ }^{\mathrm{a}}$} \\
\hline Study Abroad was a completely new topic to me & $4.5(0.7)$ \\
\hline I became apprehensive when I thought about taking this course & $2.6(1.4)$ \\
\hline Study Abroad was too complicated for me & $1.6(0.5)$ \\
\hline Pharmacists need to know how to evaluate and interpret comparative health systems & $4.0(0.6)$ \\
\hline In the future, Study Abroad should be a required course for all pharmacy students & $1.8(0.6)$ \\
\hline I see a great need for promoting Study Abroad to health care professionals & $3.4(0.8)$ \\
\hline Presently, Study Abroad is considered important by NDSU & $3.3(1.0)$ \\
\hline In the future, Study Abroad will be considered important by NDSU & $3.6(0.8)$ \\
\hline Presently, Study Abroad is considered important by pharmacy employers & $2.5(0.8)$ \\
\hline In the future, Study Abroad will be considered important by pharmacy employers & $3.0(0.8)$ \\
\hline \multicolumn{2}{|l|}{ Satisfaction with Study Abroad Activities, Mean (SD) ${ }^{\mathrm{b}}$} \\
\hline Pharmacy travel seminars (pre-pharmacy and pharmacy) & $4.0(1.0)$ \\
\hline Overview & $3.9(0.5)$ \\
\hline Financing & $4.1(0.7)$ \\
\hline Interprofessional care & $4.3(0.5)$ \\
\hline Visits (overall) & $4.4(0.7)$ \\
\hline Community pharmacy visit & $4.8(0.6)$ \\
\hline Pharmacy research center visit & $4.6(0.7)$ \\
\hline Speakers & $4.6(0.5)$ \\
\hline Pharmacy education & $4.6(0.5)$ \\
\hline Global diseases & $3.9(0.9)$ \\
\hline Comparative health systems & $4.0(1.0)$ \\
\hline Ireland health system & $4.2(0.8)$ \\
\hline United Kingdom health system & $4.2(0.8)$ \\
\hline Canada health system & $4.1(0.7)$ \\
\hline Comparative pharmacy education (US vs. Ireland) & $4.4(0.7)$ \\
\hline Student project & $4.1(0.9)$ \\
\hline Term paper writing assignment & $4.2(0.9)$ \\
\hline Term paper presentation & $4.5(0.8)$ \\
\hline \multicolumn{2}{|l|}{ Overall Study Abroad Evaluations, Mean (SD) ${ }^{\mathrm{c}}$} \\
\hline Value of material to your education & $4.2(0.4)$ \\
\hline Your background for this course & $3.7(1.0)$ \\
\hline Course organization & $3.8(1.0)$ \\
\hline Study Abroad student adviser & $4.4(1.0)$ \\
\hline Overall quality of the course & $4.6(0.5)$ \\
\hline Overall quality of the course instructors & $4.5(0.8)$ \\
\hline \multicolumn{2}{|l|}{ Demographics, \% } \\
\hline Gender, Female & 80 \\
\hline Age, $18-24$ & 80 \\
\hline \multicolumn{2}{|l|}{ What year in school? } \\
\hline Proportion Pre-Professional Pharmacy Students & 20 \\
\hline Proportion 1st Year Professional Pharmacy Students & 10 \\
\hline Proportion 2nd Year Professional Pharmacy Students & 30 \\
\hline Proportion 3rd Year Professional Pharmacy Students & 20 \\
\hline Proportion 4th Year Professional Pharmacy Students & 10 \\
\hline
\end{tabular}

${ }^{\mathrm{a}} 1=$ not at all interested to $5=$ very interested

${ }^{\mathrm{b}} 1=$ not at all satisfied to $5=$ very satisfied

${ }^{\mathrm{c}} 1=$ not at all valuable to $5=$ very valuable 
American Journal of Pharmaceutical Education 2019; 83 (8) Article 6866.

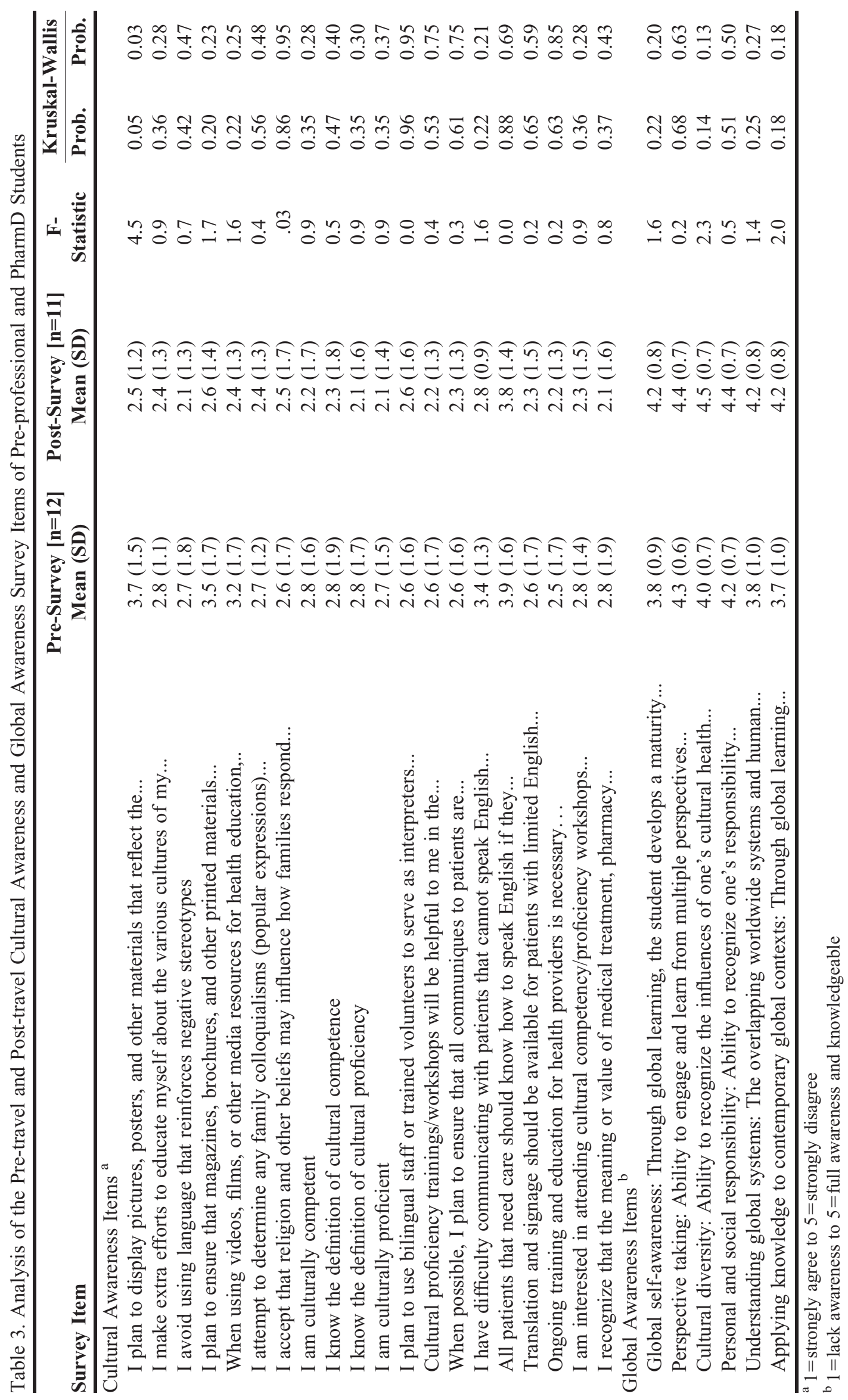




\section{American Journal of Pharmaceutical Education 2019; 83 (8) Article 6866.}

Table 4. Learning Objectives and Student Learning Activities for the Study Abroad Course in Ireland

\begin{tabular}{|c|c|}
\hline Learning Objective & Student Learning Activities \\
\hline $\begin{array}{l}\text { Describe an overview of the US and Ireland's health care } \\
\text { industry (eg, hospitals, ambulatory care, long-term care, } \\
\text { mental health care, public health system) and their various } \\
\text { responses to diseases and problems }\end{array}$ & seminars, guest speaker and reading assignments \\
\hline $\begin{array}{l}\text { Compare health care delivery and medication use in Ireland } \\
\text { with the US system }\end{array}$ & $\begin{array}{l}\text { seminars, reading assignments, guest speakers, and } \\
\text { pharmacy site visits }\end{array}$ \\
\hline $\begin{array}{l}\text { Describe the history of governmental efforts to prevent and } \\
\text { control the problems of health and disease, and the } \\
\text { professional's role in public health }\end{array}$ & $\begin{array}{l}\text { seminars, reading assignments, guest speakers, health } \\
\text { care and pharmacy site visits }\end{array}$ \\
\hline $\begin{array}{l}\text { Compare the roles of the FDA and other agencies in } \\
\text { global health }\end{array}$ & seminars, reading assignments, and guest speakers \\
\hline $\begin{array}{l}\text { Describe the potential impact of cultural values, beliefs, } \\
\text { and practices on health care delivery and health outcomes }\end{array}$ & $\begin{array}{l}\text { seminars, reading assignments, guest speakers, cultural events, } \\
\text { site visits, weekend trips, participation, and student journal }\end{array}$ \\
\hline $\begin{array}{l}\text { Evaluate one's personal and professional values and career } \\
\text { plans within the global context }\end{array}$ & $\begin{array}{l}\text { seminars, reading assignments, guest speakers, pharmacy visits, } \\
\text { cultural events, site visits, weekend trips, and student journal }\end{array}$ \\
\hline $\begin{array}{l}\text { Demonstrate written and verbal communication skills } \\
\text { regarding issues related to health and drug policy }\end{array}$ & $\begin{array}{l}\text { course participation, term paper, presentation, student journal, } \\
\text { seminars, guest speakers, site visits }\end{array}$ \\
\hline
\end{tabular}

\section{DISCUSSION}

A variety of global health training experiences have been offered by pharmacy educators in the past decade. ${ }^{15-17,26-29}$ Prescott and colleagues reported that about three-fourths of ACPE-accredited pharmacy programs provide experiential education (offered IPPEs and/ or APPEs) in global health, and about two-thirds of programs offered medical mission trips. ${ }^{17}$ However, a comparison of health care systems (especially pharmacy systems) between the US and other countries has not been adequately described. Moreover, assessments of the education provided in these courses is generally missing. This study describes an attempt to fill these gaps by incorporating a comparative health systems course into a study abroad experience in Ireland. Overall, in our three-week program, $55 \%$ of the time was devoted to professional education (seminars, guest speakers, and visits to community pharmacies), and $45 \%$ to cultural activities (eg, visits to historical and tourist sites). Results on the student course evaluation, pre- and post-travel surveys, literature review paper and presentation, and reflection paper were positive, suggesting that the course was successful in meeting its objectives.

Cumulatively, the value of our approach to incorporating global health in pharmacy education is that it provided a flexible yet comprehensive template that other pharmacy programs can adapt in a variety of ways. Pharmacy schools can also adapt our assessment processes to evaluate their own global health educational experiences more effectively. We do not suggest that study abroad experiences are the only or even the optimal means to address global health and/or cultural awareness in the professional curriculum. However, study abroad experi- ences do offer many advantages over other types of educational experiences, and several features of our approach may appeal to other pharmacy schools, depending on their unique curricular gaps and faculty expertise. One unique feature of our course setup is its flexibility. The course can be adapted for use in studying other countries and thereby provide new learning experiences for students. For example, future iterations of the course at our school will focus on London, UK, in 2017 and Vienna, Austria, in 2018, and eventually on countries on other continents. Students could potentially complete the course three times and gain different skills and experiences each time without the school having to make major changes to the course's structure and objectives.

The flexibility inherent in a study abroad course does require intentional design to ensure its effectiveness. One of the most important lessons the authors learned through this course was to use the networks and infrastructures that already existed at the college or university for study abroad programs. As an example, the instructors created a "wish list" of experiential opportunities (eg, meeting with pharmacists working in the national health system, guest speakers from local schools of pharmacy) and shared the list with IES Abroad, who used their connections in the host country to acquire some of those experiences. When an experience was not available, they provided a short list of comparable, alternative experiences that we could build into the course. Consequently, partnering with IES Abroad saved the pharmacy faculty members countless hours.

It was also important to select a host university that had a pharmacy program and would allow us to make connections with their faculty. Having access to the 


\section{American Journal of Pharmaceutical Education 2019; 83 (8) Article 6866.}

foreign pharmacy school's faculty members and facilities provides course instructors with flexibility and creativity in planning experiential activities. Partnering with local pharmacy programs will provide essential, appropriate instruction, but do so within the context of pharmacist's scope of practice in that country. This may also facilitate educational opportunities that provide the same technical skill, possibly using a different approach that is more amenable to that country's culture. As an example, in Ireland, pharmacists may obtain (via a contract with the government), the ability to dispense and administer methadone. After administering methadone to a patient, pharmacists must monitor the patients closely using a specific protocol. Teaching these skills to pharmacy students would require collaboration with local pharmacy faculty who are licensed and qualified to provide this care.

When designing the course, several factors should be considered, including the course's placement within the curriculum (to ensure that academic content aligns with experiential learning) and enrollment requirements. If too many students enroll, additional faculty and staff members must be recruited to accompany the group; if too few students enroll, the course revenues will not cover the costs. Given the planning and resources involved in developing these courses, support from the administration at the home institution is crucial. The current project was successful because it was strongly supported by the School of Pharmacy's Office of Academic Affairs and its Office of Student Affairs. Faculty members implementing study abroad courses always experience political and procedural impediments; thus, having multiple advocates is crucial to ensuring that the program is offered in a manner that is appropriate and affordable to students.

Also, the small number of students participating in the course limited our ability to quantitatively assess course outcomes. The small sample size required the use of convenience sampling as well as a descriptive statistical analysis. The use of inferential statistics was limited. Another limitation of this study is that the students who completed the course were a self-selected group of pharmacy students. These students may have been more interested in global travel than most students and therefore, more interested in and aware of the importance of cultural sensitivity and having cross-cultural experiences than other students. Thus, selection bias is a potential confounder. Therefore, our course outcomes may not be generalizable to other institutions, in part or in whole.

\section{CONCLUSION}

This manuscript describes the experience of the North Dakota State University (NDSU) School of Pharmacy in developing, implementing, and assessing a global health course intended for pharmacy students to develop an appreciation of global cultures and to compare the health care delivery system in Ireland with that in the US. Implementation of the course was successful, and student evaluations of the course indicated that the experience was informative and enriching. Future iterations of the course can easily be adapted to provide comparative pharmacy practice experiences in other European countries.

\section{ACKNOWLEDGMENTS}

The authors acknowledge Ms. Melissa Eslinger who sent out the survey.

\section{REFERENCES}

1. Brown TM, Cueto M, Fee E. The World Health Organization and the transition from "international" to "global" public health. Am J Public Health. 2006;96(1):62-72. doi:10.2105/AJPH.2004.050831.

2. Koplan JP, Bond TC, Merson MH, et al. Towards a common definition of global health. Lancet. 2009;373(9679):1993-1995. doi:10.1016/S0140-6736(09)60332-9.

3. Global Health Initiative (2008). Why Global Health Matters. Washington, DC: FamiliesUSA.

4. Macfarlane SB, Jacobs M, Kaaya EE. In the name of global health: trends in academic institutions. $J$ Public Health Policy.

2008;29(4):383-401. doi:10.1057/jphp.2008.25.

5. Transforming our world: the 2030 Agenda for Sustainable Development: Sustainable Development Knowledge Platform. https://sustainabledevelopment.un.org/. Accessed February 26, 2016. 6. Global Health Observatory data. Monitoring health for the SDGs. https://www.who.int/gho/mortality_burden_disease/en/. Accessed October 2, 2019.

7. GBD 2015 Disease and Injury Incidence and Prevalence Collaborators. Global, regional, and national incidence, prevalence, and years lived with disability for 310 diseases and injuries, 1990-

2015: a systematic analysis for the Global Burden of Disease Study 2015. Lancet 2016;388:1545-1602.

8. American Association of Colleges of Pharmacy. Global Alliance for Pharmacy Education (GAPE). http://www.gapenet.org/en-US/ Pages/default.aspx. Accessed January 23, 2015.

9. American College of Clinical Pharmacy. Practice and research networks. http://www.accp.com/about/prns.aspx. Accessed October 2, 2019.

10. Vos T, Allen C, Arora M, et al. Global, regional, and national incidence, prevalence, and years lived with disability for 310 diseases and injuries, 1990-2015: a systematic analysis for the Global Burden of Disease Study 2015. GBD 2015 Disease and Injury Incidence and Prevalence Collaborators. Lancet. 2016;388:1545-1602. https:// www.ncbi.nlm.nih.gov/pubmed/27733282. Accessed October 2, 2019.

11. Koplan JP, Bond TC, Merson MH, et al. Towards a common definition of global health. Lancet. 2009;373(9679):1993-1995. 12. Audus KL, Moreton JE, Normann SA, et al. Going global: the report of the 2009-2010 research and graduate affairs committee. Am J Pharm Educ. 2010;74(10):Article S8.

13. American Association of Colleges of Pharmacy. Global Pharmacy Education Special Interest Group of the American Association of Colleges of Pharmacy Bylaws. http://www.aacp.org/ 


\section{American Journal of Pharmaceutical Education 2019; 83 (8) Article 6866.}

governance/SIGS/global/Documents/ GlobalPharmEdSIGBylaws709.pdf. Accessed April 16, 2013.

14. Anderson C, Bates I, Beck D, et al. The WHO UNESCO FIP Pharmacy Education Taskforce: enabling concerted and collective global action. Am J Pharm Educ. 2008;72(6):Article 127.

15. Bailey LC, DiPietro Mager NA. Global health education in doctor of pharmacy programs. Am J Pharm Educ. 2016;80(4):Article 71.

16. Steeb DR, Overman RA, Sleath BL, Joyner PU. Global experiential and didactic education opportunities at US colleges and schools of pharmacy. Am J Pharm Educ. 2016;80(1):Article 7.

17. Prescott GM, Vu BN, Alsharif NZ, Prescott WA Jr. Global health education in doctor of pharmacy programs in the United States. Am J Pharm Educ. 2017;81(2):Article 28. doi: 10.5688/ajpe81228.

18. Werremeyer AB, Skoy ET. A medical mission to Guatemala as an advanced pharmacy practice experience. Am J Pharm Educ. 2012;76(8):Article 156.

19. Papanicolas I, Jha AK. Challenges in international comparison of health care systems. JAMA. 2017:318(6):515-516.

20. Rose PR. Cultural Competency for Health Administration and Public Health. Sudbury, MA: Jones \& Bartlett Publishers 2010. 21. Whitehead DM. Essential Global Learning. Association of American Colleges and Universities. Washington, DC 2016.
22. Scott DM. Assessment of pharmacists' perception of patient care competence and need for training in rural and urban areas in North Dakota. J Rural Health. 2010;26(1):90-96.

23. Dillman D, Smyth J, Christian L. Internet, Mail, and Mixed Mode Surveys: The Tailored Design Method. 3rd ed. Hoboken, NJ: John Wiley and Sons; 2009.

24. Nulty D. Adequacy of response rates to online and paper surveys: what can be done? Assess \& Eval Higher Educ. 2008;33(3):301-314. 25. IBM SPSS Statistics, Version 24, IBM Corporation, Armonk, NY. 2015.

26. Addo-Atuah J, Dutta A, Kovera C. A global health elective course in a PharmD curriculum. Am J Pharm Educ.

2014;78(10):Article 187.

27. Cisneros RM, Jawaid SP, Kendall DA, et al. International practice experiences in pharmacy education. Am J Pharm Educ. 2013;77(9):Article 188.

28. Ryan M, Cain J, Romanelli F. A survey of international activity among colleges of pharmacy in the United States. Int J Pharm Educ Pract. 2012;8.

29. Owen C, Breheny P, Ingram R, Pfeifle W, Cain J, Ryan M. Pharmacy student interest in international study. Am J Pharm Educ. 2013;77(3):Article 54. 